\title{
Impact of hydrogeological assumptions and their variation on the calculated surface uplift above flooded coal mines
}

Andre Vervoort ( $\square$ andre.vervoort@kuleuven.be )

Department of Civil Engineering

Research

Keywords: Longwall, Ground control, Surface movement, Uplift, Estimation

Posted Date: February 8th, 2022

DOI: https://doi.org/10.21203/rs.3.rs-1260245/v1

License: (c) (1) This work is licensed under a Creative Commons Attribution 4.0 International License.

Read Full License 


\section{Abstract}

Upward surface movement or uplift has been extensively observed above abandoned deep coal mines. Detailed analysis of measurements indicated that the process of uplift is a complex phenomenon. The observed uplift is linked to the flooding of the underground infrastructure and rock mass. The distribution of water pressure at the end of the mining phase and their increase during the flooding is an important aspect in all estimations. Various assumptions of this distribution at the start of the flooding phase are studied, i.e., from a zero-water pressure to a linear decrease between top and bottom longwall panel. There are also various scenarios possible of how the water pressures change as a function of time, i.e., from filling an open reservoir from bottom to top, to a systematic change in the linear downward trend. The original assumed scenario, i.e., a linear trend, remains the most likely option. It provides the best fit between the estimated uplift values and the large amount of remote sensing measurements, along northsouth transects in the Belgian Campine coal basin. However, further improvements and analyses certainly are still needed.

\section{Introduction}

During the past decades, the mining activities in entire coal districts were stopped and the underground facilities were abandoned. This was followed by the flooding of the underground, i.e., both the infrastructure and the rock mass. The latter comprises goaf material, fractured and damaged rock, and intact, but deformed strata. The main impact of this flooding was the start of upward surface movement above and around the mined areas. This process followed the many years of subsidence due to the total extraction method of longwall mining (Vervoort 2021c). One cannot overestimate enough the complexity of the process of uplift and the link between the flooding and the uplift of the earth surface. Numerous mining, geotechnical, geological, and hydrological conditions determine, in one way or another, the amount of uplift at a specific location. Hence, one must always work site specific if one would like to estimate the amount of uplift. However, my opinion is that we do not understand enough of the various mechanisms involved to start predicting uplift with enough accuracy.

At the end of 2021, I published a double paper on the surface movement above one coal mine of the Campine coal district in Belgium, i.e., the Eisden coal mine (Vervoort 2021a, b). This double paper summarized 8 years of research. The Part A paper discusses in detail the remote sensing measurements by satellites (InSAR, Interferometry with Synthetic Aperture Radar data), while the companying Part B paper presents a framework to calculate analytically the amount of uplift. The latter allows an easy comparison of various scenarios and assumptions, which helps to understand the phenomenon. For all details on the analysis of the measurements and on the proposed analytical framework, I refer the reader to this double paper, including references to other research.

The main conclusion of the analysis of the InSAR data was that a large variation is observed, both as a function of space, as of time (Vervoort 2021a). In other words, one cannot summarize the uplift by a single value or trend. The coal mine was closed in 1988 and, from October 1992 onwards, uplift was 
clearly visible above the mined zone. However, uplift also is observed in the proximity of the mined zone. The extent of uplift is at the start of the uplift phase situated in the central part and not at the boundaries of the mined zone. The average rate of movement varies over time. At the start, the maximum average rate was about $18 \mathrm{~mm} /$ year, afterwards it increased to about $23.5 \mathrm{~mm} /$ year and, about two decades after mine closure, it was about $10 \mathrm{~mm} /$ year. Due to the specific geometry of the mined area in the Campine coal basin (i.e., a relatively narrow band, orientated in the east-west direction), north-south transects show the largest variations. These north-south transects are the basis to compare calculations with measurements (see Figures further). Overall, the shape corresponds to an inverse trough, but it is not symmetrical around the middle of the mined zone, i.e., $2.625 \mathrm{~km}$. The shape also varies over time. When the largest uplift rates were observed, a distinct maximum is observed at a north-south distance of 3.625 $\mathrm{km}$. Before and after this time, plateaus of large average values with a length of 1 to $2 \mathrm{~km}$ were observed along these transects.

The analytical calculations showed a good correlation with the measurements along these transects (Vervoort 2021b). Satisfactory results were obtained when (i) the changes in pore pressure or water pressure, due to drainage, in the entire mined volume and in the surrounding rock mass are considered, and (ii) not only the expansion of the goaf volumes due to the fluid pressure being restored is considered, but also the expansion of the rest of the strata layers, i.e., the non-collapsed strata layers. The complex mining geometry in the Campine coal district was an advantage to evaluate the impact of the various components.

Although a variation as a function of time was observed, this variation was not studied in the analytical framework, published in 2021 (Vervoort 2021b). The conditions at the start of the flooding (or at the end of the mining phase) were compared to the final situation (i.e., rock mass fully saturated again). At the end of 2021, two other papers were published, covering the same theme (Zhao and Konietzky 2021; Zhao et al. 2021). Their estimations are based on numerical simulations (using the FLAC3D-code). The pore pressure distribution at the end of mining and the increase in pore pressure during flooding are different from the assumptions made in (Vervoort 2021b). As mentioned above, the proposed analytical framework allows in a relatively easy way the calculation of the impact of a change in a single parameter. Therefor the hydrogeological assumptions, applied by Zhao and Konietzky, were integrated into the case study of Eisden colliery. All other properties and assumptions of the case study remained the same. The mining geometry of the simulations by Zhao and Konietzky was not used as input in the analytical framework developed by me, as their mining geometry only consisted of one or of two mined longwall panels in their fictitious abandoned coal mine. In comparison to the very complex mining geometry of a real deep coal mine, I do not see the benefit of analysing such a simple geometry, except as a first step in a study.

\section{Hydrogeogical Assumptions}

The basic approach in the original applied framework (Vervoort 2021b) is that the end of the mining phase is characterized by a lower water pressure within an envelope around all mined longwall panels 
along a 2D north-south transect (Figure 1). The dip to the north of the strata is clearly visible in this Figure. The best results, in comparison to the measurements, were obtained when this zone was extended over $1 \mathrm{~km}$ to the north and to the south. As no measurements of water levels were available for the Campine coal basin, the assumed variation of the water pressure as a function of depth was based on measurements by David et al. 2017 and Tammetta 2013. In Figure 2a, this variation is illustrated for a column of elements. The thick blue line is the original hydraulic gradient. It is also the final situation, i.e., when the underground is again fully flooded. The hydraulic pressure at the end of the mining phase is presented by the thick brown line. In Vervoort 2021b, more details and arguments are provided, but the basic assumption is that at the top of the mined volume (i.e., oldest longwall panel), the pore pressure already is the same as the original hydraulic gradient, when the mining stopped in 1988. Above this depth, the original hydraulic gradient is observed. Below this depth, there is a linear decrease of hydraulic pressure, till a zero value is reached at the depth of the deepest longwall panel along this vertical line. The line represents the average hydraulic pressure at a specific depth. For example, within a tunnel and within the goaf volume of a recently mined panel the pressure is zero, but away from these excavations a certain water pressure can (still/again) be present. Below the deepest panel, it is assumed that the water evolves to the original hydraulic gradient over a height of $25 \mathrm{~m}$. Specifically for this paper, the increase of water pressure over time is presented in Figure $2 \mathrm{a}$ by the thinner lines. It is assumed that the change from the top panel depth downwards remains linear.

For a discussion of all other model parameters and concepts, the reader is referred to Vervoort 2021b. The most relevant ones are that a ratio of 1 on 4 is applied in the model for the mining height vs. the goaf thickness. An average vertical stiffness ratio of 1 on 10 is assumed for the goaf vs. the rest of the coal strata layers. A value of 0.25 was taken for the Poisson's ratio of all material. In absolute terms, average stiffnesses of the goaf and of the rest of the strata of $0.2 \mathrm{GPa}$ and $2.0 \mathrm{GPa}$, respectively, resulted in realistic uplift values (Vervoort 2021b).

The aim of introducing different hydraulic variations over the mined volume is to evaluate if they could provide better results for the case study of the coal mine of Eisden. Zhao and Konietzky 2021, and Zhao et al. 2021 consider completely different variations at the end of the mining phase. As the variations are only applied on a fictitious mining configuration of one or two longwall panels, some extrapolation is needed between their simple configuration and a real mine.

First, the authors make a distinction between confined and unconfined mine water. Confined means that the volume above the goaf is impermeable, while unconfined means that the volume above the goaf is considered as permeable. Earlier research clearly showed that the expansion of the goaf volumes only due to a change in water pressure does not provide realistic estimations of the uplift in the Campine coal basin (Vervoort 2021b). This is in fact the reason why the shapes of the variations of (residual) subsidence vs. of uplift along north-south transects are different (Vervoort 2016, 2020). Subsidence is mainly triggered and induced by the roof collapse in the goaf volume, while the process of uplift is more complex. So, except to illustrate this point (see further), the expansion of the goaf volumes only is not considered in this paper. 
Second, Zhao and Konietzky assume that the entire coal strata volume is completely drained and is characterised by a zero-water pressure at the end of the mining phase. The authors assume that underground pumping facilities create this condition. This is implemented into my analytical model for evaluation and comparison purposes (see Figure $2 b$, thick brown line). However, I have my doubts if this scheme is realistic. In all deep coal mines that I have visited, there is always some water seepage and water flow, which means that there is some water and water pressure differences in the surrounding volume. It is not because for example in the shaft or tunnel, there is a zero-water pressure that further away from these openings there is no water pressure. It is only in very extreme geological and hydrogeological circumstances, that I can imagine such a zero-water pressure in the entire coal strata volume, e.g., for shallow mining, seams and coal strata outcropping in hills, no shale (or other low permeable) strata, etc. In Zhao et al., 2021, one of the models (confined) presents an impermeable layer of $50 \mathrm{~m}$ thick above the goaf, characterised by a zero-pore pressure. Again, in general terms, this seems to be unrealistic. An impermeable layer does not mean that it does not contain water and, hence, that it is characterised by a zero-pore pressure. This is clearly illustrated by measurement in the deep and thick layer of the Boom clay, which is a possible host rock for nuclear waste disposal (Barnichon and Volckaert 2003; Bernier et al. 2007). Hence, the zero-pore pressure in impermeable layers is not integrated into my analytical model for evaluation and comparison purposes.

Third, Zhao and Konietzky assumes that the entire volume fills up like an open reservoir. I have translated this by the successive thin coloured lines in Figure $2 b$. They also consider various sources for the water inflow (from bottom, from sides and from above). In this and previous approaches, I have not really made this difference. For the Campine basin, I assume that there is water flow (i) from the south following the permeable strata layers, (ii) from above along permeable faults, induced fractures, and openings, and (iii) from below, as there is a pore pressure difference (e.g., between the deeper strata and the lowest mine level). However, this is not implicitly integrated in the proposed framework.

Fourth, Zhao and Konietzky (2021) consider two situations for the horizontal connections between the two goaf volumes considered, i.e., isolated vs. connected ponds. Further, I only present results for the latter. For these so-called connected ponds, I assume that first (e.g., the first $50 \mathrm{~m}$ of water column) all elements situated between $725 \mathrm{~m}$ and $775 \mathrm{~m}$ are filled. These elements are situated in the northern part only of the mined volume (north of $3.5 \mathrm{~km}$ in Figure 1). For the next $50 \mathrm{~m}$ of water, all elements between $675 \mathrm{~m}$ till $725 \mathrm{~m}$ are filled additionally and the water pressure below $725 \mathrm{~m}$ is further increased (see thin lines in Figure 2b). So, in this step, only the element columns south of a distance of $1.25 \mathrm{~km}$ are still completely dry. The situation, which Zhao and Konietzky (2021) call isolated ponds, is similar to the original analytical model (Vervoort 2021b), but the reasoning behind the latter scheme is not that these columns would be isolated from each other, but that the flow along the dip of strata plays a role.

\section{Comparison Of Various Hydrogeological Assumptions And Their Variation As A Function Of Time}


All estimations are compared to the individual InSAR measurements along a north-south transect (see Vervoort 2021a). The time series of the European C-band ERS1/2 and of the ENVISAT-ASAR satellites were used. Data were acquired for research through a European Space Agency (ESA) research proposal (Devleeschouwer et al. 2008). These data are representative for the period from August 1992 through December 2000, and the period from December 2003 through October 2010, respectively. Past analyses have shown that these data are accurate (e.g., for example Caro Cuenca et al. 2013; Vervoort 2021a) and that they provide an important source of information, which can never be realized by conventional levelling techniques. Both the spatial frequency, as the frequency as a function of time, are some orders larger than for the conventional levelling techniques.

In Figure 3, the individual InSAR-data are presented by black dots along a north-south transect, i.e., being a band with a width of $\pm 750 \mathrm{~m}$. The observed variation is partly due to the accuracy of the method, but mainly due to the variation in the east-west direction and to the impact of various types of buildings and of other reflective surfaces. A full discussion is given in Vervoort 2021a. A variation of the uplift rate was observed, combined with a spatial change in variation. Hence, three time periods are used for comparison. The first time period (Figure 3, left column; from October 1992 through April 1995) is only 2.5 years long and covers the beginning of the uplift phenomenon. The coal mine was abandoned in 1988 , followed by a short period of residual subsidence. The second and third time periods are 5 years long (Figure 3, middle and right column; from December 1995 through December 2000, and from September 2005 through September 2010, respectively). They both are situated at the end of each time series. On the various graphs, the limits of the mined zone within this north-south transect are indicated by blue square dotted lines, respectively at a north-south distance of 0.0 and $5.25 \mathrm{~km}$. The three rows of graphs in Figure 3 represent three different moments of additional water pressure in the rock mass, referring to the pressure at the bottom. The top row represents the start of the flooding, i.e., an increase in water pressure from 0 to $1 \mathrm{MPa}$. The middle row represents the increase from 2 to $3 \mathrm{MPa}$, and the bottom row rather is the situation at the end of flooding, i.e., from 5 to $6 \mathrm{MPa}$.

\subsection{Results for framework developed by Vervoort 2021b}

In the approach used in Vervoort 2021b, there was no attempt to try to determine the various values by back-analysis; rather, these values were determined by following a logical reasoning and by verifying afterwards whether a reasonable match is observed. For the latter, two criteria are used. First, the shape of the measured uplift is compared to the shape of the calculated uplift. along a north-south transect. This is done by presenting the values as a percentage of the maximum value. For the measured data, the maximum average value for the 250-m intervals is taken, and not the individual maximum value. Second, the same order of magnitude of uplift should be obtained. As the process of uplift still carries on, the final uplift is unknown and can only approximately be estimated.

In Figure 3, the first set of calculations are based on all assumptions and property values presented in Vervoort 2021b. The final case, including the various extensions, as illustrated by the envelope in Figure 1, is presented by the purple diamond shapes. The change in hydraulic pressure as a function of time (or 
stage of flooding) is as illustrated in Figure 2a. The variation between the top and the bottom of the mined volume remains linear. As the values are presented as a function of the maximum additional uplift, this linear change results in the same shape of the calculated uplift curves for the three different moments in the flooding of the underground rock mass. Hence, as the shape of the measured values changes as a function of the moment in flooding, the estimated values for this type of variation is not optimal for the three increments of water pressure considered. The main comparison in Vervoort 2021b was done for the second time period (middle column in Figure 3), which corresponds to a more than satisfactorily correlation between measurements and calculations. At the start of the uplift phase (and when there is still a larger amount of residual subsidence), there is mainly an underestimation of the measured values between the southern border of mining and the maximum of uplift (between a distance of 0 and $3 \mathrm{~km}$; Figure 3, left column). Outside the mined zone, there is an overestimation of the measured values towards the south, but not towards the north. This is most likely linked to the spreading of the uplift process over time, from the central area towards the mine borders and beyond, as illustrated in Vervoort 2021a. For the third time period in the later part of the flooding (right column in Figure 3), there is an overall (small) underestimation over the entire length of the north-south transect.

In conclusion, the estimations based on a linear change of the water pressure as a function of depth provides a satisfactorily correlation with the measurements for the central period of the uplift process, and thus of the flooding. At the start and to the end of the flooding, the overall correlation remains acceptable, but the difference between measurements and calculations is larger. Most likely, this is rather linked to a change in extension to the north and to the south of the flooded area, than to the assumed linear variation of the water pressure as a function of depth. For example, if at the start of the flooding, one would not already consider an extension to the south for the increase in water pressure, the overestimation to the south of the mined zone would be much smaller. In a similar way, a further extension of the envelope to the south, further than $1 \mathrm{~km}$ beyond the mined border, would decrease the underestimation. These conclusions and reflections again indicate that the process of uplift is complex and that one is still in the phase of understanding this process. Therefore, it is worthwhile to consider other hydraulic assumptions.

\subsection{Impact of filling up open reservoir, starting from zero water pressure in reservoir}

One of the suggestions by (Zhao and Konietzky 2021; Zhao et al. 2021) is that there is a zero-water pressure at the end of the mining phase in the mined volume (goaf volume only, or goaf, plus surrounding coal strata). One of the problems, I was confronted with, is how to best extrapolate the approach by Zhao and Konietzky 2021, explained for a fictitious and unrealistic mine geometry (a total of one, or maximum two mining panels in the entire mine) to a real mine lay-out. Here, the decision has been taken to consider the same volume with a lower water pressure as applied in Vervoort 2021b (see envelope in Figure 1), but that this volume has a zero-water pressure at the end of the mining phase. It is also assumed that the scenario is applied, which Zhao and Konietzky 2021 calls a connected situation. In other words, we assume that during the filling of this open reservoir first the volume between a depth of 775 and $725 \mathrm{~m}$ is 
filled, second between 725 and 675 m, etc. (see also thin lines in Figure 2b). For the calculations presented in Figure 3 (green circles), all other parameters are the same as for the purple diamonds, e.g., extension of drained zone to the north and to the south over $1 \mathrm{~km}$, same ratio goaf vs. coal strata, same moduli, etc.

In Figure 3, the additional uplift of both the strata and the goaf volumes is presented by green circles, while the component of the goaf volumes only is presented by red crosses. Also, the latter is presented as a percentage of the maximum uplift due to the goaf volumes only. For the initial increase in water height (from a depth of 675 to $775 \mathrm{~m}$; top row in Figure 3), the estimated uplift values show an extremely skewed shape along the north-south transect. This case should give the best correlation with the first time period (from October 1992 through April 1995; left column in Figure 3). It is clear that, over the entire length south of the maximum, the calculated values heavily underestimate the measurements. The skewed shape is far from realistic. However, north of the maximum, the estimation is closer to the measurements. For a further increase of the water level from 200 to $300 \mathrm{~m}$, in comparison to the deepest point at $775 \mathrm{~m}$, the estimated curve for the open reservoir approaches the results in Vervoort, 2021b and thus the measured values. The underestimation in the southern half is still present, but much smaller. For the last increase of water level presented (from 500 to 600 m; Figure 3 - bottom row), the differences, south of the maximum, are similar between both estimations. However, now the values for the open reservoir are larger.

If one would consider the expansion of the goaf volumes only (see curves with the red crosses in Figure 3 ), the differences between the measurements and the estimations are extremely large. It shows that integrating the goaf volumes only into a model cannot lead to realistic results. A change in the values of the goaf properties (i.e., height, stiffness, etc.) does not improve the estimated shape. It only influences the absolute values (e.g., the maximum). This confirms earlier findings (Vervoort 2016, 2021 a, b; Vervoort and Declercq 2017, 2018), i.e., the process of subsidence, triggered by the roof collapses and correlated to the goaf height and composition, is different from the process of uplift, whereby re-establishing the hydraulic gradient in the non-collapsed coal strata plays a role too. That is the reason why there is no direct correlation between the (residual) subsidence and the uplift (Vervoort, 2016, 2020; see also Discussion and conclusions below).

To illustrate that the difference between the framework developed in Vervoort 2021b and the open reservoir assumptions, based on (Zhao and Konietzky 2021; Zhao et al. 2021), is not due to the different stiffness values in both models, a calculation is done for the stiffness values by Zhao and Konietzky. As example, the combination of the second time period (from December 1995 through December 2000) with an increase in water height from $200 \mathrm{~m}$ to $300 \mathrm{~m}$ is studied. This comparison is presented in Figure 4 . Their elastic moduli $\mathrm{K}$ and $\mathrm{G}$ for goaf (i.e., $0.83 \mathrm{GPa}$ and $0.18 \mathrm{GPa}$, respectively) and strata (i.e., $15.6 \mathrm{GPa}$ and 7.6 GPa, respectively) correspond to a Young's moduli of $1.25 \mathrm{GPa}$ and $23.33 \mathrm{GPa}$, respectively (if one assumes a Poisson's ratio of 0.25 ). The values applied in Figure 3 are 0.2 and $2 \mathrm{GPa}$, respectively. The way that the latter values were determined is discussed in detail in Vervoort 2021b. It was not by back-analysis, but, rather, determined by following a logical reasoning. 
Note that the combination presented in Figure 4 corresponds to one of the combinations closest to the measurements in Figure 3. While this combination for an open reservoir still provided a reasonable approximation of the measurements, the change in stiffness values certainly does not improve the approximation. There is now a larger under-estimation of the measured values over most of the mined zone. The reason is not so much linked to the absolute values of the stiffness, but to the relative increase of the moduli ratio strata vs. goaf (from 10 on 1, to 18.7 on 1). In other words, the relative impact of the goaf has become larger and, as illustrated above, the contribution by only the goaf component is not a good approach. The total additional uplift in this phase is only $11.4 \mathrm{~mm}$ for the changed stiffness properties. For the original framework, an increase of the water pressure from 2 to $3 \mathrm{MPa}$ resulted in an additional uplift of $68.5 \mathrm{~mm}$. For the situation presented in Figure 3 (central graph), i.e., an open reservoir with same properties as in the original framework, the additional uplift is $94.9 \mathrm{~mm}$. The contribution by the goaf volumes only is less than half, i.e., $44.3 \mathrm{~mm}$.

\section{Relation Between Increase Water Pressure And Uplift}

Various researchers have observed that there is a linear relation between the observed water level and the measured uplift (e.g., Caro Cuenca 2013). Note that the increase as a function of time is not linear, both for the water level, as the uplift. After a certain time, the rate decreases. This is also observed in the case study discussed in this paper (Figure 5). The variation of the uplift is presented as a function of time from August 1992 onwards over a period of 20 years, based on InSAR-data. The mean curves are presented for 10 reflectors closest to a central point. Three points are considered, i.e., at a north-south distance equal to $0.625 \mathrm{~km}$, to $3.375 \mathrm{~km}$ (close to the maximum uplift) and to $4.625 \mathrm{~km}$. The two outside locations are approximately at the same distance from the mined limits. Note that the values for 20 years are not the final values of uplift, as today (again 10 years later), the earth surface is still moving upwards. As mentioned above, there is no data for the change in water level in the Campine coal basin.

In Figure 6, the relation between water level and uplift is presented for both sets of calculations. The increase of uplift at a north-south distance of $3.375 \mathrm{~km}$ (the location of the maximum uplift) is expressed as a percentage of the maximum calculated value at that location. For the framework developed by Vervoort 2021b, the increase in water pressure corresponds to the change in pressure at a distance of $3.375 \mathrm{~km}$. At that location, the depth of the bottom element is $725 \mathrm{~m}$. In other words, the maximum $(100 \%)$ is reached for $7.25 \mathrm{MPa}$. For the situation corresponding to an open reservoir, the increase in water pressure refers to the deepest point of the reservoir, i.e., a depth of $775 \mathrm{~m}$ in the northern part of mined area. In other words, the maximum (100\%) is reached for $7.75 \mathrm{MPa}$. As mentioned earlier, the relation for the original framework is linear (Figure 6, purple diamonds). The one corresponding to an open reservoir is not linear (Figure 6, green circles).

For the latter case, the variation of the uplift (absolute values) as a function of the increase in water pressure is presented in Figure 7. The movements at the three locations of Figure 5 are provided. So, also for a location (e.g., at $4.625 \mathrm{~km}$ ) in the deepest part of the mine, the relation is not linear. 


\section{Discussion And Conclusions}

The least one can conclude is that these additional calculations (in comparison to the ones presented in Vervoort 2021b) confirm that the process of uplift is an extremely complex process. There are still many unknowns, and one should not underestimate the problem. I remain critical to researchers who are overenthusiastic over the results of a numerical model and over the capability to predict future movements. So far, I consider the framework that I developed as a way to try to better understand the full process, and not as a way to start predicting uplift values in the future. In addition, I have spent many years interpreting in detail real and numerous measurements of this phenomenon, above several coal mines in the Belgian Campine coal basin. These interpretations show the complexity of the process, with a variation of uplift values in time and space. The large number of InSAR-measurements formed the basis to evaluate the results of the framework under development. The remote sensing data of the movement of the earth surface are extremely useful and provide detailed information. The frequency of measurements as a function of time is high, as is the amount of data points in an area with buildings and infrastructure. The analysis of these data needs of course the necessary experience and knowledge, and a good analysis is time consuming. Therefore, I do not understand the criticism formulated by Zhao and Konietzky 2021 towards the satellite data, i.e., they claim that they would have a limited accuracy and would only be interesting to observe trends. I disagree with this. They also write that "it is still difficult to observe strong local gradients produced for instance by faults (quote out of Zhao and Konietzky 2021)". However, at the same time they publish a graph in Zhao and Konietzky 2021 compiled by Caro Cuenca et al. 2013. The graph presents the variation of uplift along a transect, crossing various faults, and presenting variations at different moments. In Vervoort and Declercq 2018, the discontinuous step in the amount of uplift, based on InSAR-data, around a geological fault also is illustrated.

A first practical conclusion of the new calculations presented in this paper is a confirmation that considering the expansion of the goaf volumes only does not lead to realistic results. A change

in stiffness of the goaf material or a change of the height of the collapsed volumes will not improve the results. The complex mining geometry in the Belgian Campine coal basin allows a correct analysis of various contributions and their impact on the uplift. For example, if the geometry would be limited to single seam mining or that everywhere the same seams would be mined at the same depth and with the same thickness, incorporating the goaf volumes only in a model could give reasonable results, but it would mean that the other aspects of the uplift process are not considered. This is the reason why there is no direct correlation between (residual) subsidence and uplift. And, that there is no direct link between the uplift and the mining characteristics. The total thickness of the mined volume (between top and bottom longwall panel) is also important and the expansion of this volume due to a change of pore pressure is an important part in the total uplift. Hence, the shape of the uplift curve along a north-south transect is the sum of the shapes of the expansion of the volume of the strata between goaf volumes, and of the goaf volumes. The differences in shape between both phenomenon and the lack of correlation were clearly illustrated in Vervoort 2016, 2020. I do not understand that several European researchers do not want to accept these observations. Among others, Blachowski et al. 2019 wrote that our research 
(Vervoort and Declercq 2017) "claimed that the observed surface motions cannot be correlated with mining areas". This is of course far different from our observations and what we published in Vervoort and Declercq 2017. Zhao and Konietzky 2021 changed the conclusion in Vervoort 2020. In the latter publication it was clearly shown that there is no direct correlation between the uplift and the residual subsidence. Zhao and Konietzky 2021 changed this in "No reliable correlation between uplift and residual subsidence". It should read a "Reliable non-correlation". Of course, researchers may disagree (else there would be no progress in science), but then they should at least present reliable and detailed data to show that they observed a correlation between subsidence and uplift. As clearly illustrated by the transects above, it is not that, when the maximum of the contribution by the goaf only vs. the contribution by the rest of the strata are situated at about the same location, the full shape over the entire transect is the same for both contributions.

A second conclusion is related to the different possible distributions of the hydraulic pressures at the end of the mining phase. In the framework developed in Vervoort 2021b, a linear trend is assumed between the top longwall panel and the bottom one, along a vertical line (see above and Figure 2a). The suggestion by Zhao and Konietzky 2021 and Zhao et al. 2021 is different and they assume that there is a zero-pore pressure in the volume surrounding the mining activities at the end of the mining phase. This would be correct if one investigates open excavations, but I have my doubts if a zero-water pressure would ever be observed in the entire rock mass surrounding longwall panels. It would mean that there is no water at all and no water flow in that rock mass. Except maybe for a very particular geological and hydrogeological mining environment, it is not typical for the deep coal mining environment in Europe. The fact that they assume a zero-water pressure in the impermeable layers creates doubt that their starting hydraulic properties are correct, even that they are realistic. To be able to analyse their assumptions, I have assumed that the same volume of lower pore pressure (see envelope in Figure 1) has a zero-water pressure, and that this volume is filled by water as an open reservoir would be filled (see Figure $2 b$ ). When starting to fill from the deepest part upwards, like an open reservoir, the induced uplift values result in a very skewed shape, which is significantly different from measured shapes at the start of the uplift phase. Note that all other characteristics and assumptions were the same as in the original developed framework. This observation should be sufficient to put a question mark next to this scenario, which is called by Zhao and Konietzky 2021 the connected case. At least, this question mark is justified for most deep coal mining conditions. For this scenario, the relation between uplift and water pressure increase is non-linear, while several researchers have measured a linear relationship (e.g., Caro Cuenca 2013). The latter is seen for the original framework developed in Vervoort 2021b. Zhao and Konietzky 2021 also consider a scenario which they call isolated longwall panels, whereby the filling up of each mined and collapsed volume occur independent of the neighbouring volume. The difference with the results of the original framework is smaller, but a non-linear relationship remains between uplift and water pressure. So, the least one could conclude is that the hydrogeological assumptions and their variation, as suggested by Zhao and Konietzky 2021, are not better alternatives for the assumptions in the original framework. And, as mentioned above, I have my doubts if these alternatives are realistic for most deep coal mines. 
For the final conclusion of this paper, I like to repeat a quote out of Vervoort 2021b: "Although a reasonable match is realised between measurements and calculations, the developed framework cannot be considered to be final. Advanced hydrogeological modelling could lead to some more information about the distribution of the water pressure at the end of the mining period and, more specifically, the extent of the drained area." However, the latter will not be simple as very little information is available on the state of the entire rock mass and on the hydrogeological conditions.

\section{Declarations}

\section{Declarations by author:}

\section{List of abbreviations}

No abbreviations are used in the text

\section{Ethical Responsibilities of Authors}

I, as author, fully agree with the following ethical responsibilities:

This journal is committed to upholding the integrity of the scientific record. As a member of the Committee on Publication Ethics (COPE) the journal will follow the COPE guidelines on how to deal with potential acts of misconduct.

Authors should refrain from misrepresenting research results which could damage the trust in the journal, the professionalism of scientific authorship, and ultimately the entire scientific endeavour. Maintaining integrity of the research and its presentation is helped by following the rules of good scientific practice, which include:

- The manuscript should not be submitted to more than one journal for simultaneous consideration.

\section{[Not submitted elsewhere]}

- The submitted work should be original and should not have been published elsewhere in any form or language (partially or in full), unless the new work concerns an expansion of previous work. (Please provide transparency on the re-use of material to avoid the concerns about text-recycling ('selfplagiarism'). [The paper is an extension of previous work, but it is clearly indicated]

- A single study should not be split up into several parts to increase the quantity of submissions and submitted to various journals or to one journal over time (i.e. 'salami-slicing/publishing'). [It is not the case, and it has been clearly discussed in text]

- Concurrent or secondary publication is sometimes justifiable, provided certain conditions are met. Examples include: translations or a manuscript that is intended for a different group of readers. [NA]

- Results should be presented clearly, honestly, and without fabrication, falsification or inappropriate data manipulation (including image based manipulation). Authors should adhere to disciplinespecific rules for acquiring, selecting and processing data. [It is the case] 
- No data, text, or theories by others are presented as if they were the author's own ('plagiarism').

Proper acknowledgements to other works must be given (this includes material that is closely copied (near verbatim), summarized and/or paraphrased), quotation marks (to indicate words taken from another source) are used for verbatim copying of material, and permissions secured for material that is copyrighted. [No plagiarism; three short quotes are included, to illustrate my point; proper references are given]

\section{Ethics approval and consent to participate}

"Not applicable" (i.e., no experiments conducted)

\section{Consent for publication}

"Not applicable"

\section{Availability of data and materials}

At this moment the raw data have not been released to be open to the public.

\section{Competing interests}

There are no financial or non-financial competing interests for me (I am the only author).

\section{Funding}

There were no external sources of funding for conducting this research.

\section{Authors' contributions}

I am the only author and I have done all the analysis myself.

\section{Acknowledgements}

NA.

\section{References}

1. Barnichon J-D, Volckaert G (2003) Observations and predictions of hydromechanical coupling effects in the Boom clay, Mol Underground Research Laboratory, Belgium. Hydrogeology J 11:193202. http://dx.doi.org/10.1007/s10040-002-0240-6

2. Bernier F, Li X-L, Bastiaens W (2007) Twenty-five years' geotechnical observation and testing in the Tertiary Boom Clay formation. Géotechnique 57(2):229-237.

3. https://doi.org/10.1680/geot.2007.57.2.229 
4. Blachowski J, Kopec A, Milczarek W, Owczarz K (2019) Evolution of secondary deformations captured by satellite radar interferometry: Case study of an abandoned coal basin in SW Poland. Sustainability 11:884. http://dx.doi.org/10.3390/su11030884

5. Caro Cuenca M, Hooper AJ, Hanssen RF (2013) Surface deformation induced by water influx in the abandoned coal mines in Limburg, the Netherlands observed by satellite radar interferometry. $\mathrm{J}$ of Applied Geophysics 88:1-11. http://dx.doi.org/10.1016/j.jappgeo.2012.10.003

6. David K, Timms WA, Barbour SL, Mitra R (2017) Tracking changes in the specific storage of overburden rock during longwall coal mining. $J$ of Hydrology 553:304-320. http://dx.doi.org/10.1016/j.jhydrol.2017.07.057

7. Devleeschouwer X, Declercq PY, Flamion B, Brixko J, Timmermans A, Vanneste J (2008) Uplift revealed by radar interferometry around Liège (Belgium): A relation with rising mining groundwater. In: Proceedings of the symposium post-Mining 2008, Nancy.

8. Tammetta P (2013) Estimation of the height of complete groundwater drainage above mined longwall panels. Groundwater (NGWA) 51(5):723-734 (and comments by author (2014) on discussion, Groundwater (NGWA) 52(3):339-342).

9. Vervoort A (2016) Surface movement above an underground coal longwall mine after closure. Nat Hazards Earth Syst Sci 16:2107-2121. https://doi.org/10.5194/nhess-16-2107-2016

10. Vervoort A (2020) Long-term impact of coal mining on surface movement: residual subsidence versus uplift. Min Rep Glückauf 156(2):136-141.

11. Vervoort A (2021a) Uplift of the surface of the earth above abandoned coal mines. Part A: Analysis of satellite data related to the movement of the surface. Int J Rock Mech Min Sci 148:104896. https://doi.org/10.1016/j.ijrmms.2021.104896

12. Vervoort A (2021b) Uplift of the surface of the earth above abandoned coal mines. Part B:

Framework to understand and explain uplift. Int J Rock Mech Min Sci 148:104947.

https://doi.org/10.1016/j.ijrmms.2021.104947

13. Vervoort A (2021c) Various phases in surface movements linked to deep coal longwall mining: from start-up till the period after closure. Int J Coal Sci Technol 8:412-426. https://doi.org/10.1007/s40789-020-00325-0

14. Vervoort A, Declercq PY (2017) Surface movement above old coal longwalls after mine closure. Int J Min Sci Technol 27(3):481-490. https://doi.org/10.1016/j.ijmst.2017.03.007

15. Vervoort A, Declercq PY (2018) Upward surface movement above deep coal mines after closure and flooding of underground workings. Int J Min Sci Technol 28:53-59. https://doi.org/10.1016/j.ijmst.2017.11.008

16. Zhao J, Konietzky H (2021) An overview on flooding induced uplift for abandoned coal mines. Int J Rock Mech Min Sci 148:104955. https://doi.org/10.1016/j.ijrmms.2021.104955

17. Zhao J, Konietzky H, Herbst M, Morgenstern R (2021) Numerical simulation of flooding induced uplift for abandoned coal mines: simulation schemes and parameter sensitivity. Int J Coal Sci Technol 8:1238-1249. https://doi.org/10.1007/s40789-021-00465-x 


\section{Figures}

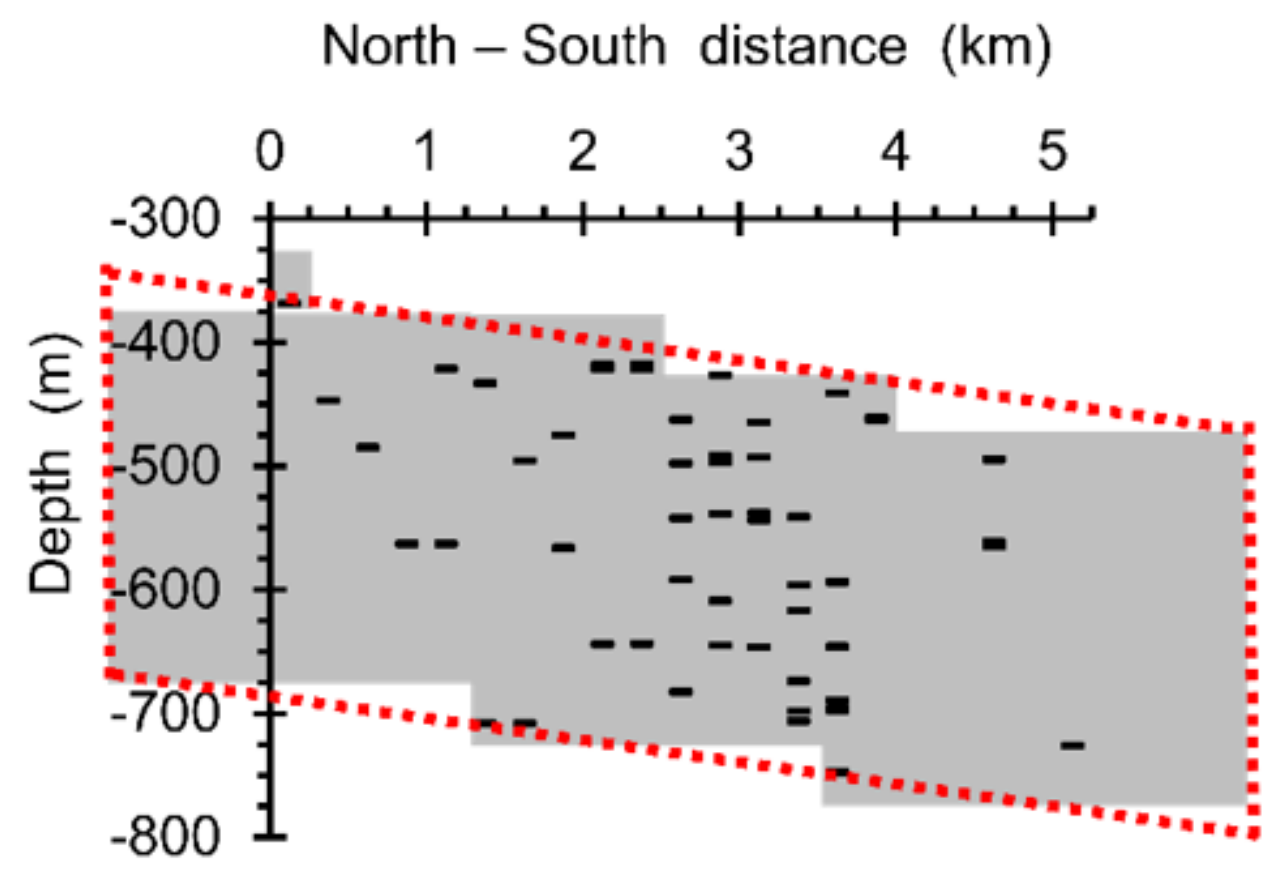

Figure 1

Illustration of the basic 2D-model: envelope around all mined longwall panels (indicated by short black lines), including an extension of $1 \mathrm{~km}$ to north and to south, with a lower water pressure. The red dotted line follows the average dip of the strata. The grey shaded area is the discretization of the envelope, taking the dimensions of each element into account, i.e., a height of $50 \mathrm{~m}$ and a north-south distance of $250 \mathrm{~m}$. 
Hydrostatic pressure (MPa)

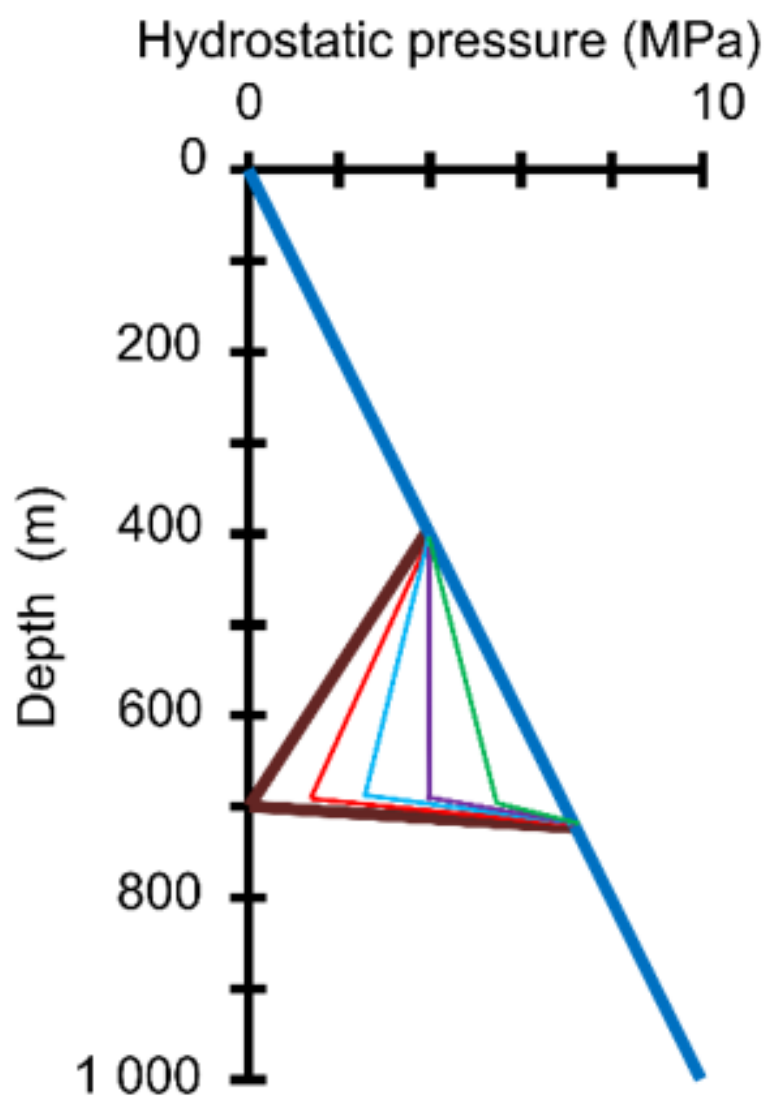

a.
Hydrostatic pressure (MPa)

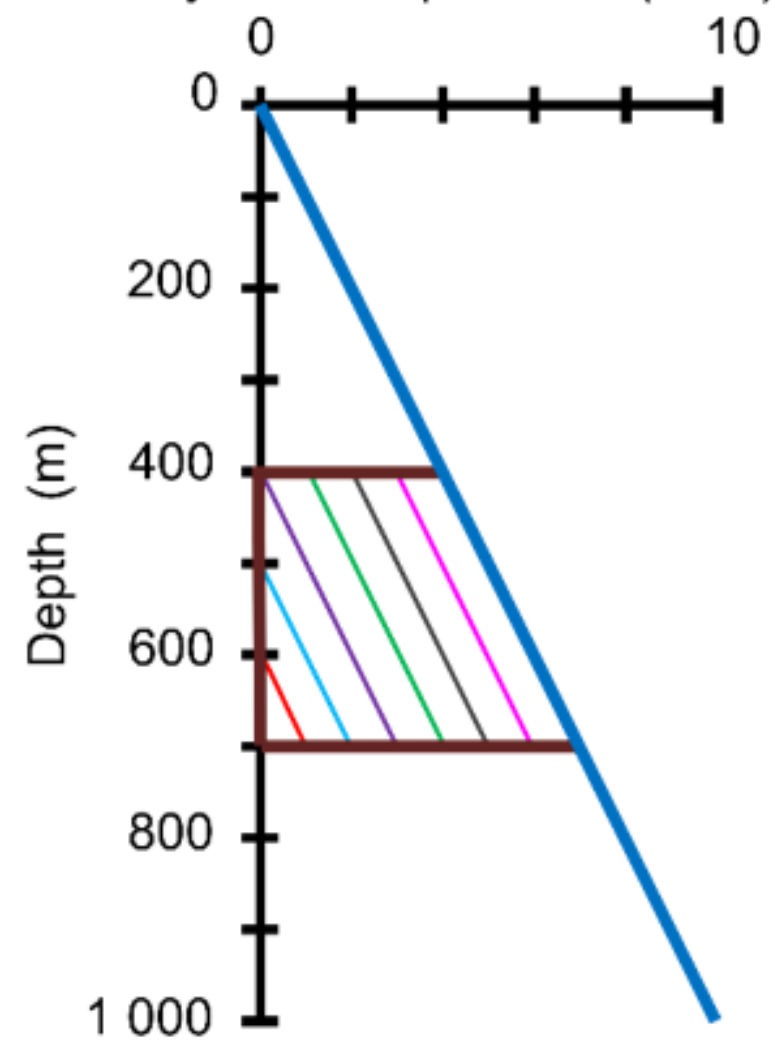

b.

Figure 2

Assumed variation of the water pressure as a function of depth for the situation that along this line the top longwall panel is situated at a depth of $400 \mathrm{~m}$ and the bottom panel at a depth of $700 \mathrm{~m}$. a. based on the approach by Vervoort 2021b; b. adapted from the assumptions by Zhao and Konietzky 2021 and Zhao et al. 2021. 


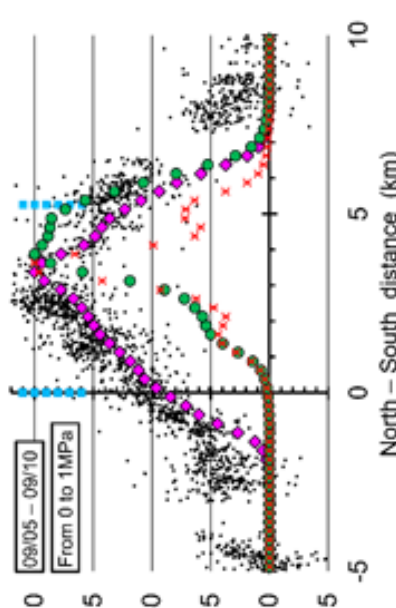

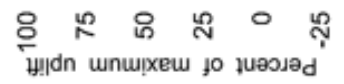

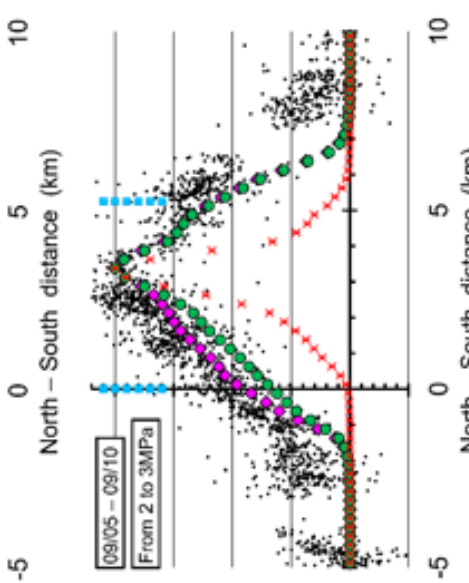

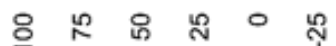
b!ldn wnuixew to łuesed
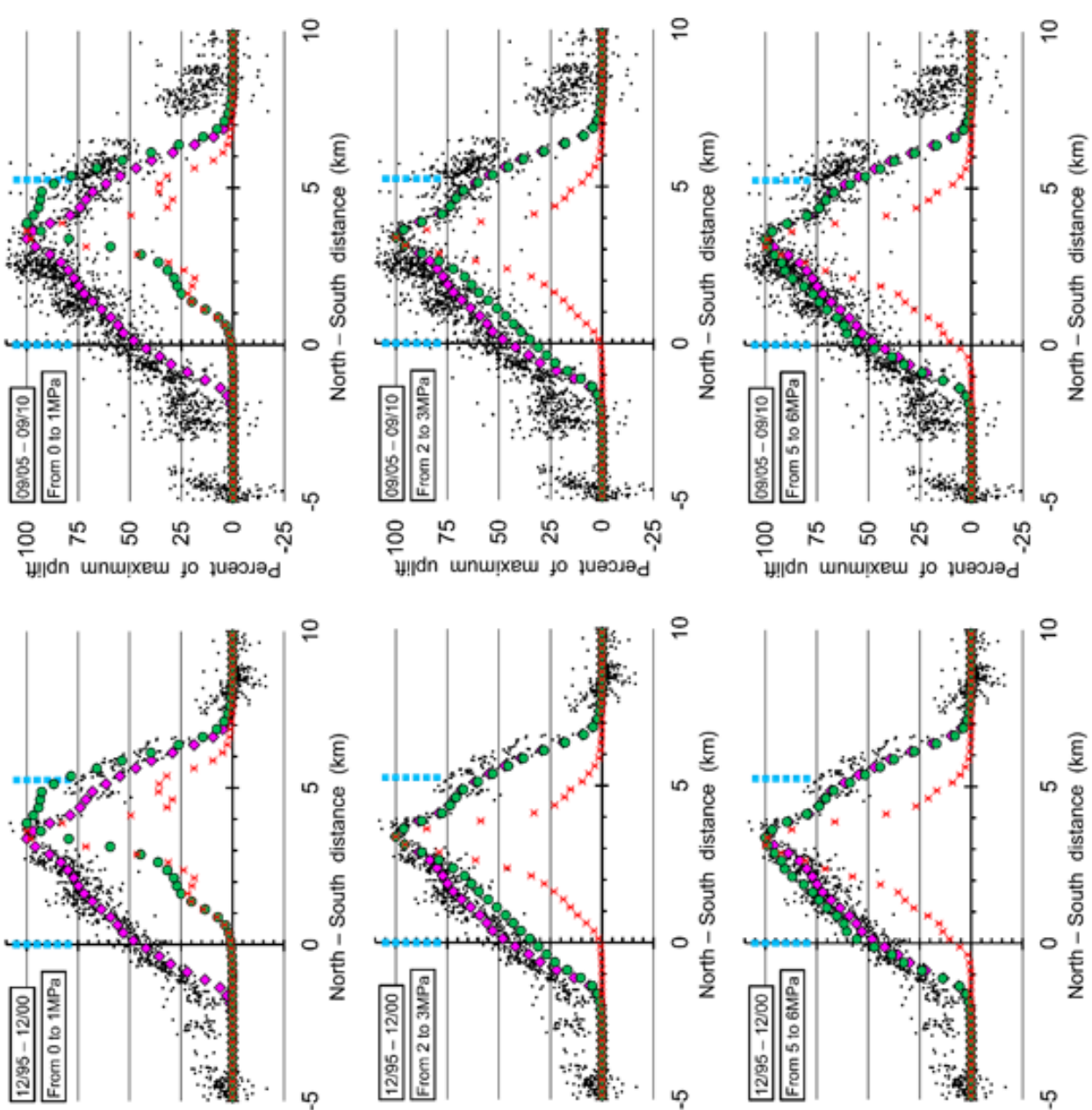

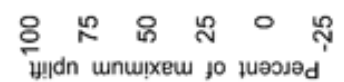

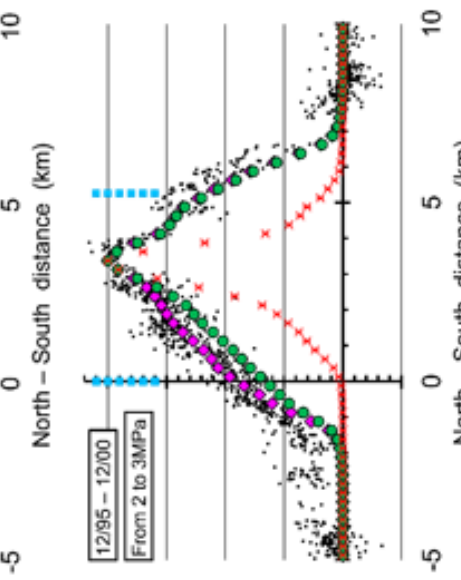

은 品

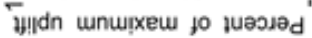

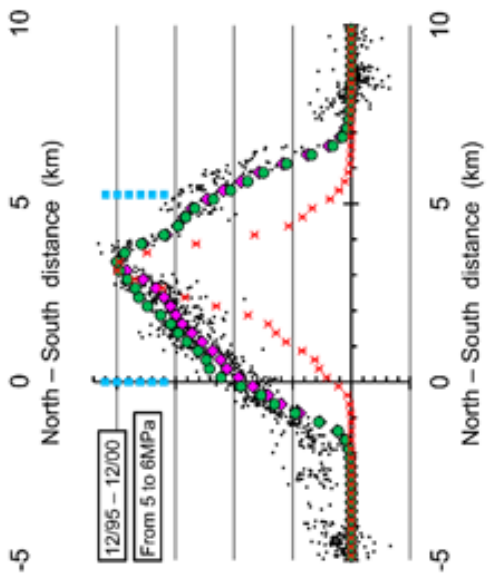

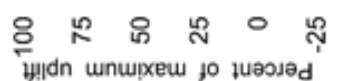

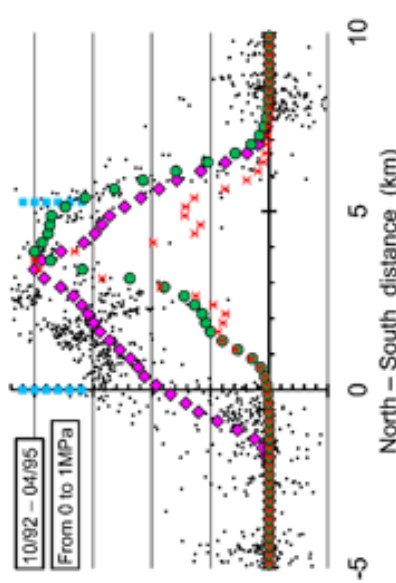

용 ํำ

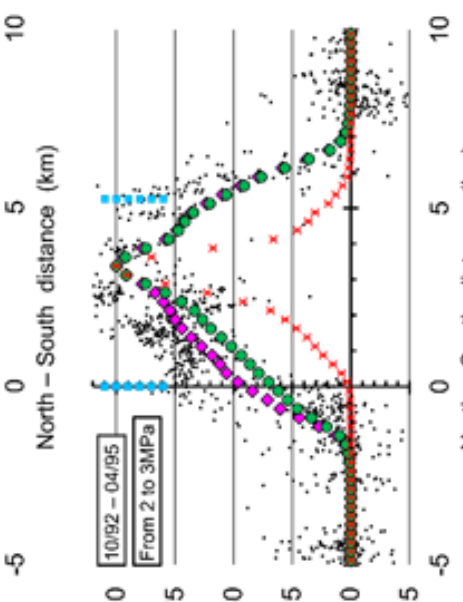

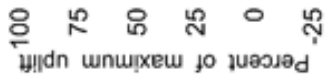

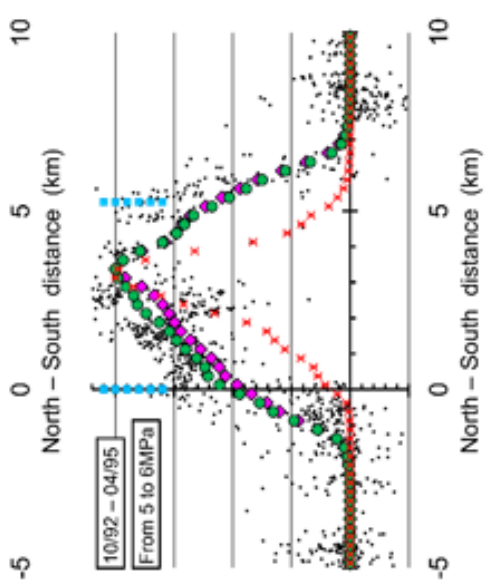

ำ

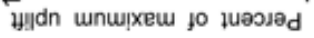

\section{Figure 3}

Comparison between InSAR data for three different time periods (black dots), estimations based on framework and property values developed in Vervoort 2021b (purple diamonds) and estimations for open reservoir scenario (green circles for contribution by goaf volume and rest of coal strata, and red crosses for contribution by goaf volumes only). The three time periods are from October 1992 through April 1995 (left column), from December 1995 through December 2000 (middle column) and from September 2005 
through September 2010 (right column). Three different increases in water height are presented (the same increase is presented per row; see labels and explanation in text). The limits of the mined area are indicated by blue square dotted lines.

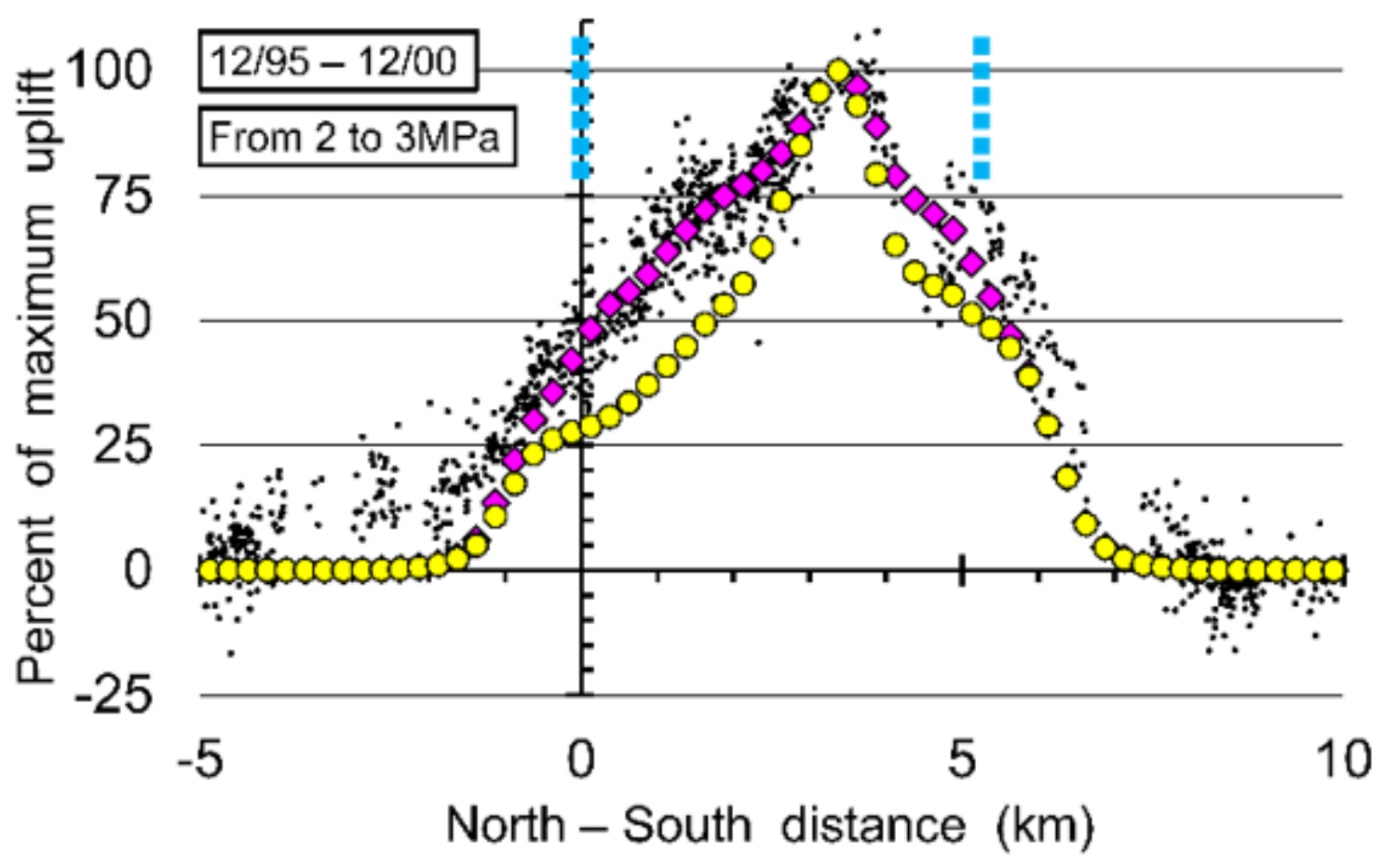

Figure 4

Comparison between InSAR data for the 5-year period from December 1995 through December 2000 (black dots), estimations based on framework and property values developed in Vervoort 2021b (purple diamonds) and estimations for open reservoir scenario and for moduli, as applied by numerical models of (Zhao and Konietzky 2021; Zhao et al. 2021) (yellow circles), whereby the water column changes from $200 \mathrm{~m}$ to $300 \mathrm{~m}$. The limits of the mined area are indicated by blue square dotted lines. 


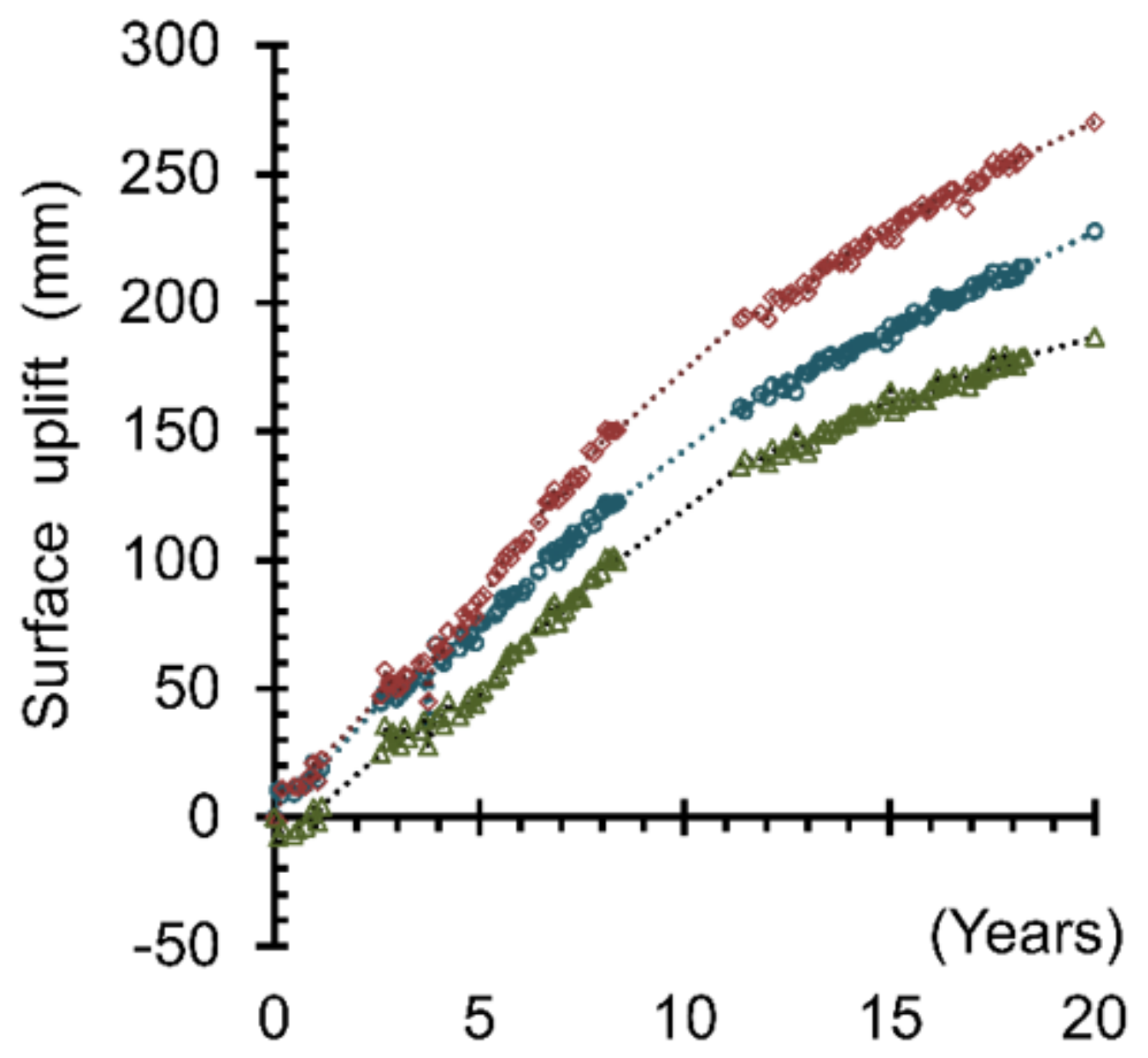

Figure 5

Variation of the uplift as a function of time from August 1992 onwards over a period of 20 years, based on InSAR-data. The mean curves are presented for 10 reflectors closest to a central point: green curve around a north-south distance equal to $0.625 \mathrm{~km}$, burgundy curve around $3.375 \mathrm{~km}$, and blue curve around $4.625 \mathrm{~km}$. 


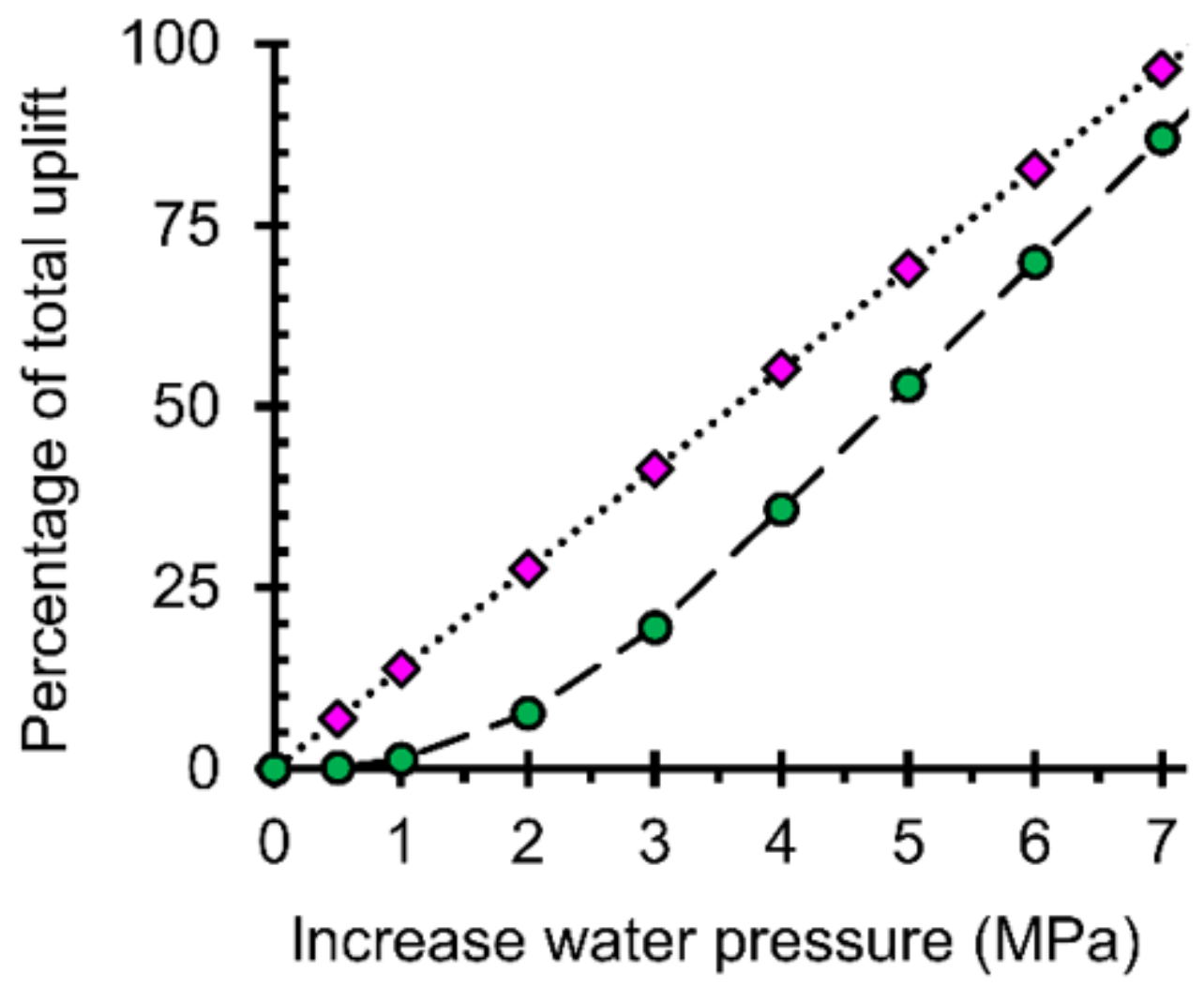

Figure 6

Relation between the amount of uplift at a north-south distance of $3.375 \mathrm{~km}$ and the increase of water pressure. The uplift is presented as a percentage of the maximum calculated amount of uplift at 3.375 $\mathrm{km}$. The relation for the framework developed by Vervoort, 2021b is presented by purple diamonds and the model assuming an open reservoir is presented by green circles. 


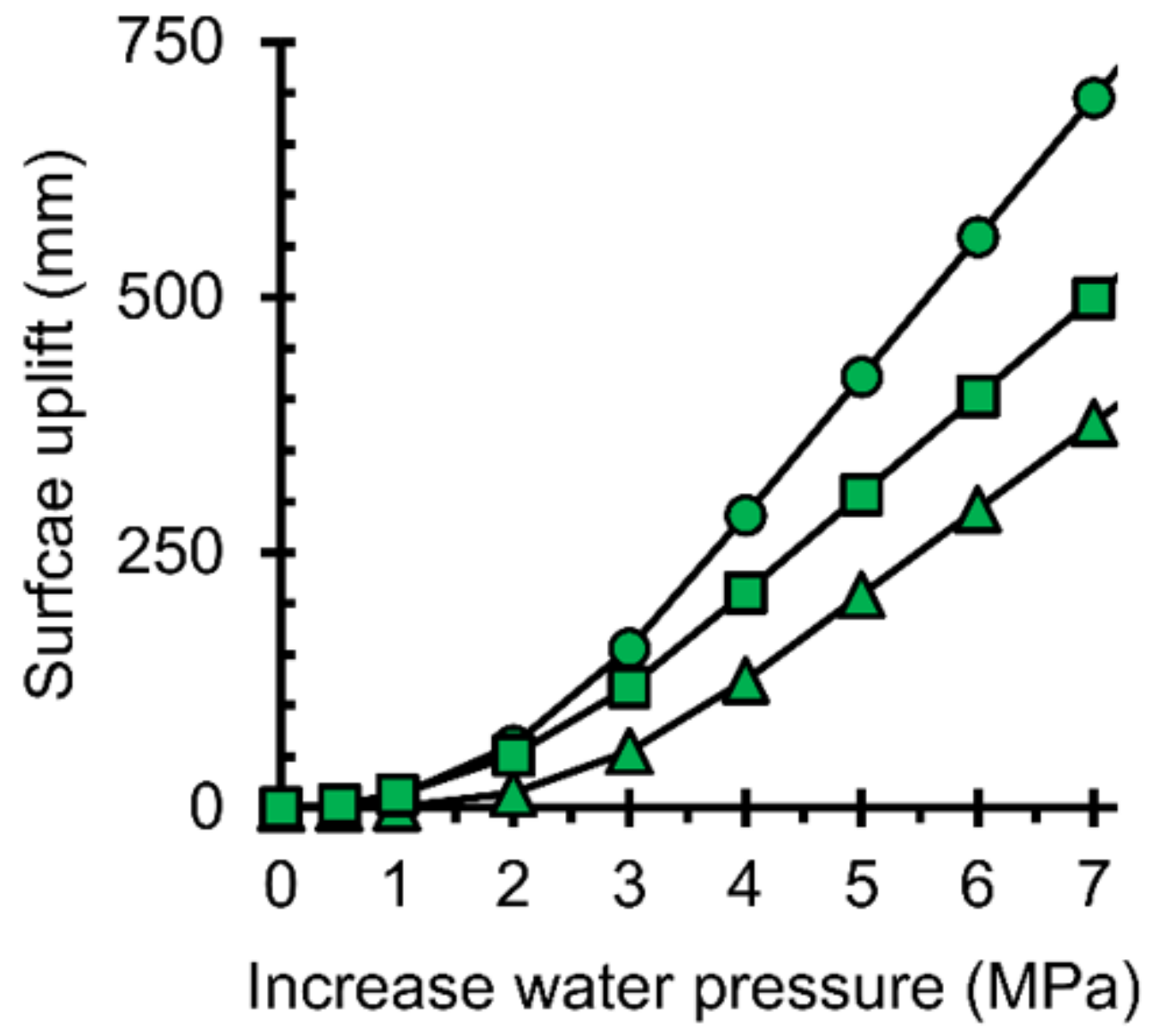

Figure 7

Variation of the amount of uplift as a function of the increase of water pressure for the scenario of an open reservoir. Information is presented for three north-south distances: triangles presenting the distance of $0.625 \mathrm{~km}$, circles for $3.375 \mathrm{~km}$ and squares for $4.625 \mathrm{~km}$. 